\section{THE HAEMORRHAGIC DISORDERS}

By M. Stefanini, M.D., and W. Dameshek, M.D. Pp. xii +368 , with 143 illustrations New York: Grune and Stratton. 1955 .

This " clinical and therapeutic approach" (as the subtitle states) to the haemorrhagic disorders comes from the pens of two well known men from Tufts University, Boston, Mass. Stefanini has worked on these problems for a good many years, both in Italy and India as well as in the United States, and Dameshek is the editor of " Blood " and a fine lecturer and teacher. As part of the introduction a list of synonyms of terms used for blood coagulation factors is given. In the present confused state of terminology this is particularly useful.

A discussion of the normal haemostatic process with diagrams of the various hypotheses and tables indicating the action, site of production and characteristics of the clotting factors and the disease entities caused by their deficiencies, is followed by a classification of the haemorrhagic disorders, which reads rather like the " 57 causes of purpura, which you ought to remember for your examinations." The defects of the vascular factors include scurvy, hereditary haemorrhagic telangiectasia, anaphylactoid purpura and even pulmonary haemosiderosis. The thrombocytopenic states are divided into amegakaryocytic and megakaryocytic groups, the latter including "idiopathic thrombocytopenic purpura." These, in the reviewer's opinion are ugly words and will not be accepted readily by other haematologists; in both "primary" and "secondary" thrombocytopenia there may be many megakaryocytes, although not maturing properly, in the marrow or they may be relative hypoplasia. Splenectomy and adrenocortical therapy are carefully considered, as indeed they should be in every case of this nature. In the right case they produce good results.

Deficiency of blood clotting factors includes haemophilia and related conditions, the hypoprothrombinaemias, and fibrinogenopenia. Other conditions discussed are thrombocythaemia with purpura in spite of the many platelets in the blood, liver disease causing a bleeding tendency, circulating anti-coagulants, "fibrinolytic purpura," foetal and neo-natal bleeding states and the dysproteinaemias, such as multiple myelomatosis and amyloidosis. The therapeutic and genetic aspects of haemor- rhagic disorders are the subjects of the last two chapters. In the appendix the techniques used in the study of these problems are briefly outlined. The list of references contains more than $75^{\circ}$ papers and ranges from the classical studies up to date. There is a useful subject index.

Most of the photographs are very good, and well reproduced; many of the tables, however, although didactically sound, are rather difficult to survey and therefore less valuable. Altogether this is a helpful book on a difficult subject and ought to be a standby for the investigator of haemorrhagic tendencies for a good while to come.

E.N.

\section{NURSING CARE OF THE NEWLY BORN INFANT}

By W. S. Craig, B.Sc., M.D., F.R.C.P., M.R.C.P., F.R.S.E., in collaboration with 4 others. Pp. viii +472 , with 225 illustrations. Edinburgh: E. \& S. Livingstone Ltd. 1955. 35s.

Unrivalled in the field of paediatric nursing, this book is constructively planned beginning with a consideration of the midwife as a paediatric nurse. An account of the growth, development and nourishment of the foetus follows. Adjustments on the part of the newly-born baby at birth are noted, some of the minor departures from normal being covered. The book ends with a selection of clinical problems and nursing procedures and a chapter on laboratory and therapeutic aids. There is also a useful glossary.

The text is clearly printed and easily readable, pervaded by common sense and allowing for contrasting conditions and opinions. It is generously illustrated with charts, line drawings and photographs, some of which are coloured. Emphasis is on clinical observation and nursing care.

It is an excellent book for nurses and midwives, and especially valuable to students working in the paediatric field.

M.A.L.

\section{SUBPHRENIC ABSCESS}

By H. R. S. Harley, M.S., F.R.C.S. Pp. $x i+2$ r6, with $4 \mathrm{I}$ illustrations. Oxford: Blackwell Scientific Publications. 1955. 35s.

This monograph is a most comprehensive study 